\title{
Research Article \\ Effects of Supply Chain Strategy on Stump Fuel Cost: A Simulation Approach
}

\author{
Anders Eriksson, ${ }^{1}$ Lars Eliasson, ${ }^{2}$ Per-Anders Hansson, ${ }^{1}$ and Raida Jirjis ${ }^{1}$ \\ ${ }^{1}$ Department of Energy and Technology, Swedish University of Agricultural Sciences, P.O. BOX 7032, 75007 Uppsala, Sweden \\ ${ }^{2}$ Skogforsk (The Forestry Research Institute of Sweden), Science Park, 75183 Uppsala, Sweden \\ Correspondence should be addressed to Anders Eriksson; anders.kg.eriksson@slu.se
}

Received 4 April 2014; Accepted 12 June 2014; Published 30 June 2014

Academic Editor: Harri Mäkinen

Copyright (C) 2014 Anders Eriksson et al. This is an open access article distributed under the Creative Commons Attribution License, which permits unrestricted use, distribution, and reproduction in any medium, provided the original work is properly cited.

In Sweden, stump fuel extraction for energy purposes is not a well-established practice and this major resource is currently left in the forest. The stump fuel supply chain is both challenging and complex, due to distance between resource and end user, material bulkiness, and the number of subprocesses involved. This study examined the impact of different aspects such as site characteristics, fuel quality, biomass losses, and machine performance on fuel cost. Two systems, including transport of comminuted and uncomminuted fuel, were studied. Discrete-event simulation was used to model systems and to analyse the dynamics of the supply chain and its various components. For a distance of $10 \mathrm{~km}$, transportation of uncomminuted fuel gave the lowest costs. For distances from 30 to $70 \mathrm{~km}$, site size (odt) determined whether to comminute or not before transport. For longer distances, comminution before transport proved to be necessary. Well-planned stump storage was shown to reduce the delivery costs significantly, while high moisture content $(>45 \%)$ had detrimental effects on system costs per unit energy delivered. However, the most influential parameters were productivity level and site characteristics (distance and site size).

\section{Introduction}

Conventional bioenergy assortments, mainly forest industry by-products such as black liquor, bark, sawdust, and shavings, are already utilised to a great extent in Sweden. The potential for growth and development in the bioenergy sector lies in primary forest fuels, for example, small trees, logging residues, and tree stumps, in other words materials previously left in the forest. The largest volume of biomass is in the tree stump assortment, which is currently almost unused $[1,2]$.

If properly handled, trees stumps are a high-quality fuel [3]. Today softwood tree stumps are harvested on a limited scale in Sweden, but national potential of $20.7 \mathrm{TWh}$ per year has been reported [2]. Due to the stumps geometry of root system, spruce-dominated final felling stands are mainly considered suitable for stump extraction [4]. Extraction can be based on energy and silvicultural considerations [5]. Heat and combined heat and power plants (CHP) are the main consumers of stump fuel today [6]. Other future areas of potential application include biorefineries, liquid biofuel production, and thermal treatment plants [7-9].

Stumps are usually harvested using an excavator in the snow-free season when the ground is not frozen, that is, late spring, summer, and early autumn in the Nordic countries [6]. For both practical and environmental reasons, not every single stump is harvested. The Swedish Forest Agency recommends leaving $15-25 \%$ of stumps for environmental reasons, since stump wood can act as a habitat for different fungi, mosses, bryophytes, and insects $[10,11]$. Forwarding of stumps to long piles at roadside landings is often done with the same type of forwarder as is used for logging residues [1]. The stumps are later transported to a terminal or directly to the end user. Stumps need to be comminuted to a hog fuel before they can be used by end users. Transport and comminution of stumps can be organized in different ways and can involve different vehicles and machines [12]. Comminution can be performed directly at landings, at terminals, or at the end user facility $[6,13]$, using mobile 
or semimobile comminution units [14]. In addition, there are some end users with large-scale stationary comminution equipment [6]. Moreover, there are systems that integrate both comminution and sieving at forest landings to separate the reject fraction from the accepted fraction $[15,16]$. Logging residues are often comminuted at forest landings in order to improve the transport properties of the fuel [1]. Such systems have gained interest for stump fuel as well, since uncomminuted stumps are bulky.

The end user is often a large CHP plant converting stumps to heat and power [17]. The highest demand for fuel is concentrated in the cold winter season. A time lag between production and demand is one of the reasons behind the need for stump storage [18]. Another reason is that the fuel quality of newly harvested stumps does not meet the quality requirements set by end users. Storage of woody biomass can alter the fuel quality through chemical, biological, and physical processes [19] and may improve fuel quality by reducing the ash content $(\mathrm{AC})$ and the moisture content (MC). An unacceptably high AC in newly harvested stumps, mainly owing to contamination by soil, is the main obstacle to reach the desired fuel quality. The storage time required to reduce the AC is often very long, creating adverse effects for the whole system. Moreover, the fuel quality fluctuates during the year, partly depending on storage form (whole, split, or crushed stumps). Long-term storage has a negative effect on energy content due to dry matter losses (DML) caused by microbial degradation, which reduce the amount of available fuel $[3,20,21]$. Rauch provides a calculation scheme considering the tradeoff between changes in MC and DML, among other factors, due to long-term storage [22].

All activities within the supply chain can influence the fuel quality. Therefore it is important to manage the fuel properly and to reduce losses throughout the supply chain in order to deliver an acceptable fuel at a competitive price. Management of logistics issues within the supply chain can determine the fate of an emerging industry [23]. Allen et al. [24] concluded through modelling that logistic costs represent a significant proportion of total costs in forest fuel systems. Net revenue is influenced by both the quality and the amount of fuel delivered. A smaller amount of fuel delivered or lower fuel quality means less energy units for cost allocation. Stump quantity and location also influence total costs in the system. Large variations in machine productivity in different working environments and for different machine types and operators have been reported [17, 25]. All these factors and their interaction make the supply chain difficult to overview. One way to enable a system overview is to build simulation models of the supply chain. Simulation is often preferable to real (full-scale) field studies for both practical and economic reasons.

Sensitivity analysis has previously been used as a tool to analyze the impact of various model parameters in simulation of biomass systems [26]. Ghaffariyan et al. [27] and Acuna et al. [28] used a similar approach to study the effects of operational factors within forest residue supply chains. Moreover, An and Searcy [29] employed discreteevent simulation (DES) to analyze new concepts in biomass logistics and to evaluate several factors linked to design and performance. The use of DES as a tool in decision making has increased in recent decades. In many areas it is the most frequently used research technique due to its flexibility and analysis potential. In contrast to static modelling, DES can incorporate uncertainties, interactions between system components, and interdependencies within the supply chain [30].

This study examined the question of how stump fuel supply chains should be managed to deliver a product to a competitive price. The objective was to evaluate the importance of different factors related to biomass losses, fuel quality, machine performance, and site characteristics on the cost of fuel delivery.

\section{Methodology}

2.1. Description of Systems Studied. Two different stump fuel supply chains were considered in the analyses and selected to represent two different locations for comminution and thereby two different transportation options. Both systems have been proven to operate efficiently irrespective of the operating conditions, but they represent two different logistics regimes [12]. The systems general structure is similar and therefore suitable for the further analyses. The initial processes, harvesting, forwarding, and storage, are common for the two systems. An excavator equipped with a specially designed stump lifter head that uproots the stumps and shakes them to get rid of soil contaminants is used for stump harvesting. This excavator is moved between sites on a lowbed trailer. The harvested stumps are collected with a forwarder and placed at a roadside landing. The forwarder is also moved between different sites on a lowbed trailer. The stump material is stored at the forest landing before transport or comminution $[3,17]$.

The second set of processes differs between the systems studied on a conceptual level with regard to location of the comminution process. System (I) utilizes a mobile truck or trailer-mounted grinder [31] for stump crushing at the roadside landing and a self-loading chip truck, equipped with crane and bucket, for fuel transport. An alternative subsystem with sieving in combination with comminution, enabling shorter storage requirement, a reduction in AC, a potential reduction in $\mathrm{MC}$, higher possible harvesting productivity, less fine fraction material, and general quality assurance, was also studied. System (II) utilizes a loose residue stump truck for transportation of whole stump pieces to the end user, where they are comminuted using a large stationary crusher. Both transport systems, irrespective of fuel type delivered, include the following activities: driving out to a roadside landing, loading material, driving to the end user, and unloading material. For fuel unloading, side tipping was considered in system (I) and grapple unloading into a stationary crusher in system (II).

Material losses occur at all stages within the systems. Already in the clear cutting area, some of the stumps are not harvested for practical and environmental reasons. Locating and lifting every single stump at a harvesting area is timeconsuming. During gathering of stumps and forwarding 


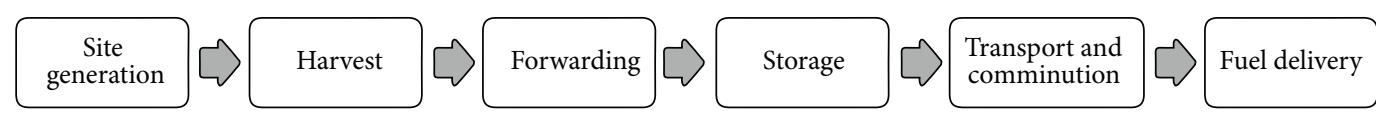

FIGURE 1: Model and process structure in the proposed supply chain simulation model with the different submodules included.

TABLE 1: Average/approximate data on various activities and specifications reported in the literature.

\begin{tabular}{lccc}
\hline Activity & Units & Value & Reference \\
\hline Harvesting & odt $^{*} / \mathrm{h}$ & $2.5-6.5$ & {$[17,47,48]$} \\
Forwarding & odt $/ \mathrm{h}$ & $4-11$ & {$[17,25,48]$} \\
Mobile comminution & odt/h & $5-23$ & {$[49,50]$} \\
self-loading chip truck & & & \\
$\quad$ Cargo volume & $\mathrm{m}^{3}$ & 120 & {$[51]$} \\
$\quad$ Payload & tonne & 30 & {$[51]$} \\
$\quad$ Loading time & min & $41-73$ & {$[51]$} \\
$\quad$ Unloading time & min & $14-23$ & {$[51]$} \\
Loose stump truck & & & {$[35,39,52]$} \\
$\quad$ Cargo volume & $\mathrm{m}^{3}$ & $105-155$ & {$[52]$} \\
$\quad$ Payload & tonne & 27 & {$[39,52,53]$} \\
$\quad$ Loading time & min & $25-80$ & {$[39,52,53]$} \\
$\quad$ Unloading time & min & $30-60$ & {$[54]$} \\
Stationary comminution & odt/h & $15-50$ & \\
\hline
\end{tabular}

* odt-oven-dry (metric) tonne.

them to the landing, some stumps remain in the clear cut. Similar, some material is lost at landing while, for example, loading from the ground [32, 33]. If sieving is included, further material losses occur through the reject fraction $[15$, $16,34]$. Dry matter losses also occur during storage, due to material degradation. The material losses at different stages are expressed in relation to the ingoing material meaning that losses at one stage result in less ingoing material at the next supply chain activity.

Upon delivery of stumps to CHP plants, the material is normally weighed and samples are taken for MC determination. The load weight and the MC value are used to calculate the approximate energy content in each load, which is later used in accounting to determine payment for the contractor. The degree of contamination due to, for example, stones and gravel is often not measured for each load in practice, although it can considerably affect the energy content.

2.2. Supply Chain Data. Listed intervals for activity times (Table 1) can be found under average operating conditions. In extreme cases, values outside the intervals have been reported [35]. In modelling, error and uncertainty may be present in both model and data. A distinction can be made between aleatory uncertainty (inherent stochastic variation in the system studied) and epistemic uncertainty (inaccuracy due to lack of knowledge or incomplete information). Error often refers to inaccuracies arising not due to lack of knowledge, and a distinction can be made between acknowledged and unacknowledged errors $[36,37]$. The systems studied here had variations in process times and outcomes, mainly due to differences in study site characteristics and prevailing weather conditions, work procedure, machines used and their specifications, and the human factor represented by the operator [17, $38,39]$. System variation is also possible through deliberate choices within the design representing, for example, system modifications, different forms of work organization, and strategies. Fuel quality fluctuates and has stochastic elements affected by weather conditions and microbial degradation. A MC of $40-50 \%$ wet weight basis (w.b.) in newly harvested stumps, decreasing during summer storage to around $25 \%$ in early autumn before the rewetting process begins, has been reported $[3,21]$. In general, stump $\mathrm{MC}$ is below $30 \%$ in summertime and below $40 \%$ in wintertime [40]. A MC of roughly $20 \%$ has been reported after 13-16 months of windrow storage. Ash content and DML values in the range of $1-10 \%$ dry weight basis, depending on storage time and harvesting method, have also been reported [3].

2.3. Simulation Overview. The dynamics of transport and comminution of stump fuel were studied using the DES approach described by Eriksson et al. [12]. The present work extended that ExtendSim simulation model further developed it by including submodules for harvesting, forwarding, and storage to better match the objectives of the study. Submodules for site generation and fuel delivery were also developed (Figure 1).

The model was programmed to enable variations (stochastic or deterministic) in 15 predefined study factors (SF) related to handling, fuel quality, machine efficiency, and site characteristics (Table 2).

A total time for machine movement between harvesting sites of 60 minutes for the mobile comminution unit (truckor trailer-mounted) and a driving time of 30 minutes for the transport truck were assumed. A maximum allowed payload of 30 and 27 tonnes was assumed for the trucks in systems (I) and (II), respectively. A basic density value for stump wood of $430 \mathrm{~kg}$ dry weight $(\mathrm{dw}) / \mathrm{m}^{3}$ and a solid volume content (SVC) of 20 and $35 \%$ were used for loose and crushed stumps, respectively [12]. Moreover, a calorimetric value on an ashfree basis $\left(\mathrm{CV}_{\mathrm{afb}}\right)$ of $20.5 \mathrm{MJ} / \mathrm{kg} \mathrm{dw}$ was assumed [41]. All machines included were operated for two eight-hour daily shifts. The values used for hourly machine costs (Table 3 ) are based on the results of previously reported cost calculations $[12,34]$ and an exchange rate of $€ 1=$ SEK8.5. Hourly costs used are net calculations from a contractor's point of view and include wages but not margin for profit or risk. The time consumed in moving the excavator and forwarder on a trailer between sites was assumed to be $3 \mathrm{~h}$, at a cost of $150 € / \mathrm{h}$ and machine.

2.4. Structure of Supply Chain Models. At the start, 10 areas suitable for stump harvest were generated (Figure 2). Conditions for site size in terms of oven-dry (metric) tonnes 
TABLE 2: List of the selected study factors (SF1-15) and their predefined low (-1), expected (0), and high levels (1).

\begin{tabular}{|c|c|c|c|c|c|}
\hline & \multirow[t]{2}{*}{ Study factor } & \multirow{2}{*}{ Units } & \multicolumn{3}{|c|}{ Study factor levels } \\
\hline & & & Low $(-1)$ & 0 & High (1) \\
\hline$\overline{\text { SF1 }}$ & Stumps left in ground & $\%$ & 30 & 20 & 10 \\
\hline SF2 & Stumps left by forwarder & $\%$ & 10 & 5 & 0 \\
\hline SF3 & Stumps left at landing & $\%$ & 5 & 2.5 & 0 \\
\hline SF4 & MC after storage & $\%$ & 40 & 30 & 20 \\
\hline SF5 & AC after storage & $\%$ & 6 & 3 & 1.5 \\
\hline SF6 & DML after storage & $\%$ & 7 & 5 & 3 \\
\hline SF7 & Harvest productivity & odt/PMH & 3.5 & 4.5 & 5.5 \\
\hline SF8 & Forwarding productivity & odt/PMH & 5 & 8 & 11 \\
\hline SF9 & Crushing productivity & odt/PMH & $7 / 30^{*}$ & $10 / 40$ & $13 / 50$ \\
\hline SF10 & Loading time & $\min$ & $70 / 65$ & $55 / 45$ & $40 / 25$ \\
\hline SF11 & Unloading time & $\min$ & $25 / 75$ & $20 / 60$ & $15 / 45$ \\
\hline $\mathrm{SF} 12$ & Cargo volume & $\mathrm{m}^{3}$ & $113 / 138$ & $120 / 145$ & $127 / 152$ \\
\hline SF13 & Truck payload & tonne & $27 / 24$ & $30 / 27$ & $33 / 30$ \\
\hline SF14 & Distance & $\mathrm{km}$ & 100 & 60 & 20 \\
\hline SF15 & Site size & odt & 100 & 300 & 500 \\
\hline
\end{tabular}

${ }^{*}$ When two values are given, the first is for system (I) and the second for system (II).

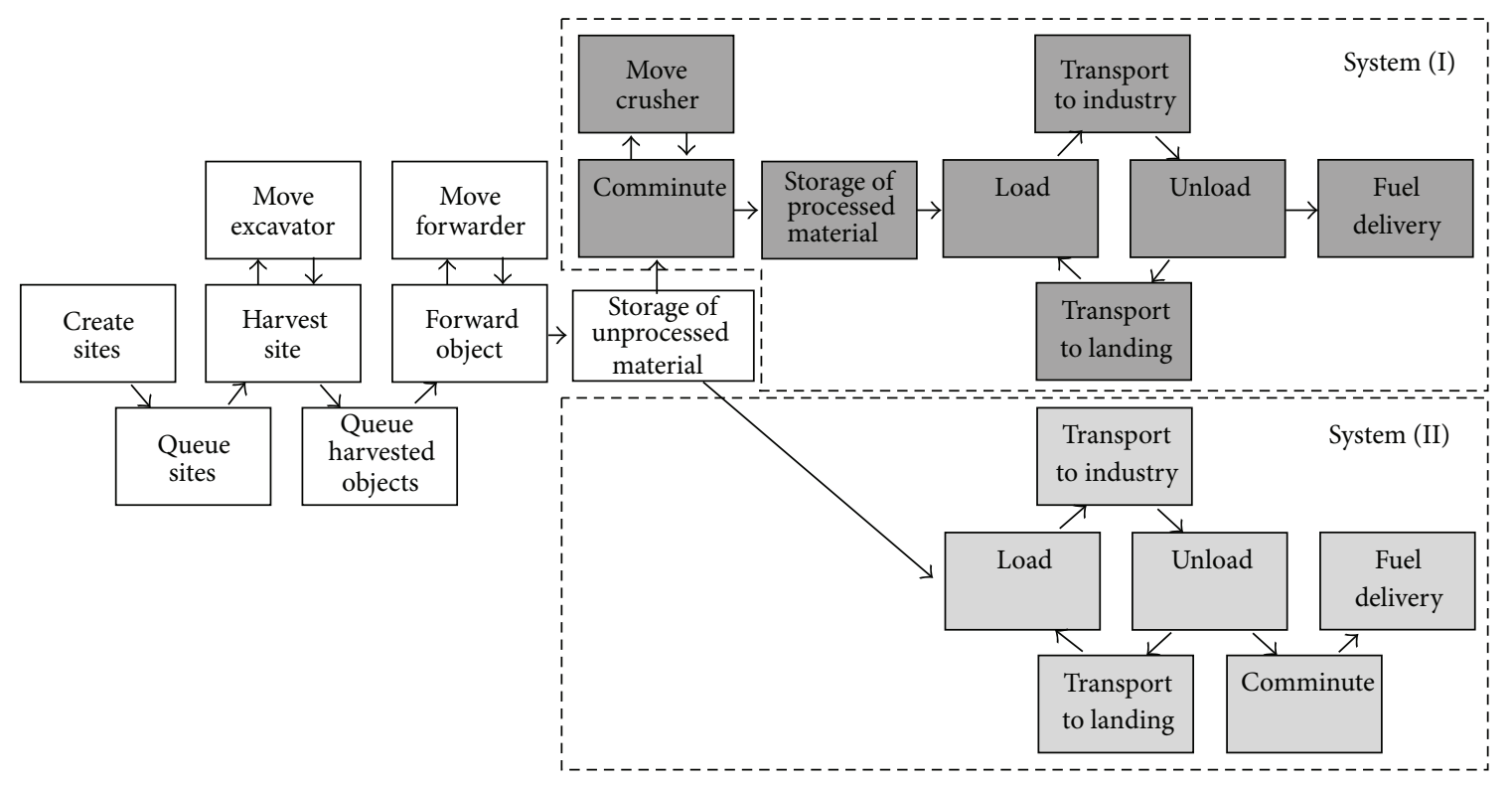

FIGURE 2: Flow diagram of the supply chain model showing the two systems tested, (I) and (II).

(odt) of stumps in the ground per site and road transport distance to the end user $(\mathrm{km})$ were defined in advance and read from a Microsoft Excel input spreadsheet. Settings for effectiveness, activity times, and productivity values for all processes within the supply chain were also defined before the simulation started and read from the same input data spreadsheet. In addition, conditions for all biomass losses within the supply chain, fuel quality parameters, and machine specifications were defined prior to simulation.

The simulation procedure is as follows. An area is randomly selected from those available. The model directs an excavator to the first site. The excavator harvests a designated share of all stumps at that site. After stump lifting, harvest time, $\mathrm{CV}_{\mathrm{afb}}$, basic density $\left(\rho_{\text {basic }}\right)$, SVC for loose material, initial MC (wet basis), and $\mathrm{AC}$ (both natural $\left(\mathrm{AC}_{\text {nat }}\right)$ and one derived from contaminants $\left.\left(\mathrm{AC}_{\text {cont }}\right)\right)$ are set and stored in attributes associated with each entity (odt stumps). The values used in this study are listed in Section 2.3. All harvested stumps from each site are grouped together (batched) into a new object and placed in a queue while waiting to be further handled. The model directs the excavator to the next site and repeats the procedure until all sites generated are harvested.

Once all stumps are harvested, a forwarder is directed out to the first object in the queue of harvested ones. It starts to collect the harvested biomass according to the input settings and gather it in a new queue. The model directs the forwarder to the next object and repeats the procedure until all harvested sites are forwarded. 
When it is time for transport and possibly comminution, new values are set for the fuel quality-associated attributes MC and AC. Moreover, DML are deducted from total dry mass.

In system (I), a mobile comminution unit is directed to every site, one at a time, and transforms the stored stumps to hog fuel. A new value for the parameter SVC is set after comminution, which enables more efficient truck transport. If sieving at the landing is included, a share of the dry mass is deducted as reject and new values for $\mathrm{MC}$ and $\mathrm{AC}$ are set. The comminuted material from each location is batched together into a new object and placed in a queue while waiting to be handled.

The trucks in systems (I) and (II) are directed to the first object in the queue of stored and potentially comminuted stumps. The load capacity can be limited by weight or volume. A given number of odt, calculated through a comparison of the legal truck payload and the volumetrically possible load based on the attributes of the stump material and the truck, are loaded on each truck. Potential fuel losses caused by direct loading from the ground are deducted. The truck and stump fuel entities are batched together and transported to the end user, where the fuel entities are unloaded and the truck and fuel are unbatched. If the material is uncomminuted it is directly crushed. Time for transport is calculated based on transport distance and an empirical formula for average driving speed described in [35]. The empty trucks return to the landing and repeat the procedure. If there is not enough material at that particular landing, the truck drives to the next one and continues to load. A more detailed description of transport and comminution can be found in the original model [12].

The simulation model calculates the amount of energy delivered based on the sum of energy quantities associated with each odt fuel (lower heating value dry basis $\left(\mathrm{LHV}_{\text {d.b. }}\right)$ calculated by (1)) $[42,43]$. Both the number of odt delivered and the fuel quality parameters (MC and $\mathrm{AC}$ ) determine the final amount of MWh delivered:

$$
\begin{aligned}
\mathrm{LHV}_{\mathrm{d} . b .} & \\
=\frac{1}{3.6}( & \left(\mathrm{CV}_{\mathrm{afb}}-2.444 * 8.936 * \frac{\left[\mathrm{H}_{2}\right]}{100}\right) \\
& * \frac{100-\mathrm{AC}}{100} \\
& \left.-\left(2.444 * \frac{\mathrm{MC}}{100-\mathrm{MC}}\right)\right)(\mathrm{MWh} / \text { odt }),
\end{aligned}
$$

where $\mathrm{CV}_{\text {afb }}$ is calorific value, ash-free basis $(20.5 \mathrm{MJ} / \mathrm{kg} \mathrm{dw}$ [41]), AC is total ash content, $\mathrm{dw}$ basis, 2.444 is the enthalpy difference between gaseous and liquid water at $25^{\circ} \mathrm{C} \mathrm{MJ} / \mathrm{kg}$, 8.936 is the molar mass ratio between water $\left(\mathrm{H}_{2} \mathrm{O}\right)$ and hydrogen $\left(\mathrm{H}_{2}\right),\left[\mathrm{H}_{2}\right]$ is hydrogen content in stored stump wood (6.075 [3]), and MC is moisture content, wet basis.

When all possible portions of the initial stumps generated are delivered to the end user, both the number of odt and total amount of energy delivered are written to an output spreadsheet. The cost of each process, calculated based
TABLE 3: Hourly machine costs used in the simulations.

\begin{tabular}{lcc}
\hline Machine & Units & Hourly cost \\
\hline Excavator & $€ / \mathrm{h}$ & 88 \\
Forwarder & $€ / \mathrm{h}$ & 100 \\
Self-loading truck & $€ / \mathrm{h}$ & 100 \\
Stump truck & $€ / \mathrm{h}$ & 105 \\
Mobile comminution unit & $€ / \mathrm{h}$ & 170 \\
Screening/sieving unit & $€ / \mathrm{h}$ & 30 \\
Stationary comminution unit & $€ / \mathrm{h}$ & 265 \\
\hline
\end{tabular}

on activity time and hourly cost, is written to the same spreadsheet.

The face validity of the model was checked by trying to uncover errors and detect faults using a subjective method called structured walkthrough. Evaluation of model logic and internal structure was performed. Visualization was also used as a verification and validation tool during model execution [44]. The model was found to be reasonable based on these tests.

2.5. Experimental Design. Simulation experiments were conducted to examine both the expected outcome and the importance of different factors. At the start, a factor screening experiment was conducted and 15 preidentified study factors were examined. The factors were varied one at a time from the defined low level $(-1)$ to the high level (1), while the others were held constant at their predefined 0-level, which also enabled investigation of potential nonlinear individual effects. These levels were chosen to represent a poor, expected, and good case. Thus the figures were not extremes but were intended to reflect common variations within the systems studied based on current knowledge. Systems (I) and (II) were evaluated when operating in a geographical area with 10 stump harvesting sites.

To further study potential nonlinear responses, an extended parameter investigation was conducted. In this case the parameters were varied one at a time outside the previously defined low and high levels, while the others were held constant at their previously defined 0-level. To capture and investigate the effects of stump harvesting area selection and to reflect different categories of sites that could occur in real-life operations, an extended site characteristic experiment was conducted. Transport distances $(10-150 \mathrm{~km})$ and site sizes $(75-600 \mathrm{odt})$ were analysed.

The effects of introducing sieving in combination with landing comminution for heavily contaminated material were also examined. The effects of an AC of $20 \%$ before comminution lowered to $5 \%$ after sieving and rejection of $25 \%$ dry matter were simulated. In the simulation of a sieving system, a DML during storage of $2 \%$ instead of the base case of 5\%, a MC of $27 \%$ instead of $30 \%$ as in the base case, and $10 \%$ higher harvest productivity were considered. Less time spent by the excavator to shake stumps will lead to higher stump lifting productivity $[17,33]$. 


\section{Results and Discussion}

3.1. Factor Screening. A dynamic supply chain simulation model was developed to simulate different situations. Total system costs per unit energy delivered (€/MWh) (hereafter "fuel cost") were chosen as the performance metric in the following analyses. The experimental frame when all study factors were simultaneously changed from their low value $(-1)$ to their high value (1) (defined in Table 2) was 10.6 to $30.0 € / \mathrm{MWh}$ for system (I) and 10.3 to $30.2 € / \mathrm{MWh}$ for system (II). This clearly highlights the importance of proper planning, operation, management, and storage throughout the supply chain. The large experimental frame obtained meant that economic system output was strongly influenced by the 15 study factors tested.

A factor screening experiment was conducted in which each factor was changed individually from its 0 -level to its low value $(-1)$ and high value (1). The results indicated that the most important factors were those related to machine productivity (SF7, SF8, and SF9) and site characteristics (SF14 and SF15) (Figure 3). In particular, the machines operating out in the forest (stump lifter, forwarder, and mobile comminution unit) made a significant impact on total fuel cost. In practice, these parameters are difficult to forecast. A stump fuel supply chain is therefore difficult to assess in advance.

A simultaneous change in all study factors, either to the low or to the high case, gave values close to the sum of change in each factor individually. The presented change in fuel cost can be related to the fuel cost for systems SI and SII being 16.6 and $17.1 € / \mathrm{MWh}$, respectively, in the base case (0).

3.2. Material Losses. Every time material is handled, energy and resources are invested in the process. The energy delivered must be compared with the system input in terms of machine time and cost. In our simulations, not harvesting some stumps at the start (SF1) had minor negative effects on the fuel costs, since no time was invested in those entities. A total cost increase of around 3.5-4\% could be expected if $40 \%$ of the stumps were left in the ground at the start compared with harvesting all (Figure 4). The small negative effect was related to the relatively high cost of machine movement. Leaving behind $10 \%$ of the harvested stumps when forwarding (SF2) resulted in a cost increase of around 4.5\% at system level (Figure 4). Loading material directly from the ground at the landing results in material losses, since the uneven surface makes it impossible to load everything. This lost material at the landing has been harvested, forwarded to the roadside, stored for some time, and possibly comminuted; that is, much unnecessary work has been done, since the contractors responsible for upstream processes have handed a fuel that is never delivered. Material losses of $6 \%$ at the landing (SF3) generated a cost increase of 5.6\% and 3.5\% for systems (I) and (II), respectively (Figure 4). In system I, every percentage point of lost material resulted in a cost increase of $0.10 \%, 0.45 \%$ and $0.93 \%$ for SF1, SF2, and SF3, respectively. In system II, similar losses resulted in a cost increase of $0.09 \%, 0.43 \%$ and $0.58 \%$ for the same factors. In a systems perspective, losses that occur after a process will affect all upstream processes. This means that losses that occur at a late
TABLE 4: Effects on fuel cost ( $€ / M W h)$ of changing storage outcome from a low to a high case by simultaneously changing all related parameters (moisture content, ash content, and dry matter losses) in systems (I) and (II).

\begin{tabular}{lcc}
\hline \multirow{2}{*}{ System } & \multicolumn{2}{c}{ Fuel cost $(€ / \mathrm{MWh})$} \\
& Low case & High case \\
\hline S (I) & 17.9 & 15.7 \\
S (II) & 18.6 & 16.3 \\
\hline
\end{tabular}

stage in the supply chain affect more processes than earlier stage losses and contribute to a more expensive fuel.

3.3. Storage Outcome and Fuel Quality. The effects of storage on fuel quality (MC, AC, and DML) are difficult to predict since they can be influenced by the initial conditions, storage time, prevalent weather, and storage form. General guidelines on how to store stumps exist, but the outcome of storage varies. In our simulations, a cost decrease of around $12.5 \%$ was seen when all storage-related parameters were set at their best level (1) compared with their worst (-1), which highlights the importance of proper storage (Table 4). However with time, quality parameter values of $\mathrm{AC}$ and $\mathrm{MC}$ usually improve, while DML decrease the amount of stumps. The input values (MC, AC, and DML) used in the model represented what is normally observed in common practice. This cost reduction can be achieved passively and costly during storage, in contrast to, for example, investment in a machine unit with higher productivity.

Almost linear effects were found in the extended parameter analysis when $\mathrm{AC}$ and DML were changed, while varying MC had a nonlinear effect on cost (Figure 5). The MC strongly affected both the heating value and the truck load weight, which explains the nonlinear curve. Pettersson and Nordfjell [45] concluded that MC is the most influential quality factor affecting calorific value, storage properties, and transportation cost. A large increase in fuel cost occurred when a fuel with MC higher than $35 \%$ was transported in system (I), whereas system (II) was more tolerant to fuel MC. This is because uncomminuted stumps are bulky and the loads are limited by volume rather than weight. The cost difference between handling a fuel with $15-35 \% \mathrm{MC}$ and a fuel with $\mathrm{MC}$ in the region of $45-55 \%$ was large, especially for system (I). Avoiding fuels with a high MC was crucial for system viability. A poststorage MC of $35 \%$ compared with $55 \%$ reduced the fuel cost by $17 \%$ for system (I) and $10 \%$ for system (II).

3.4. Machine Productivity. As described earlier, machine productivity values can vary considerably. Identical study conditions are unattainable in nature and beforehand predictions based on assumed conditions are difficult to achieve. In our simulations, changes in machine performance caused significant changes in system outcome. When studying the effect of simultaneously changing all factors related to machine productivity (SF7-11) from a low to a high level, a cost 


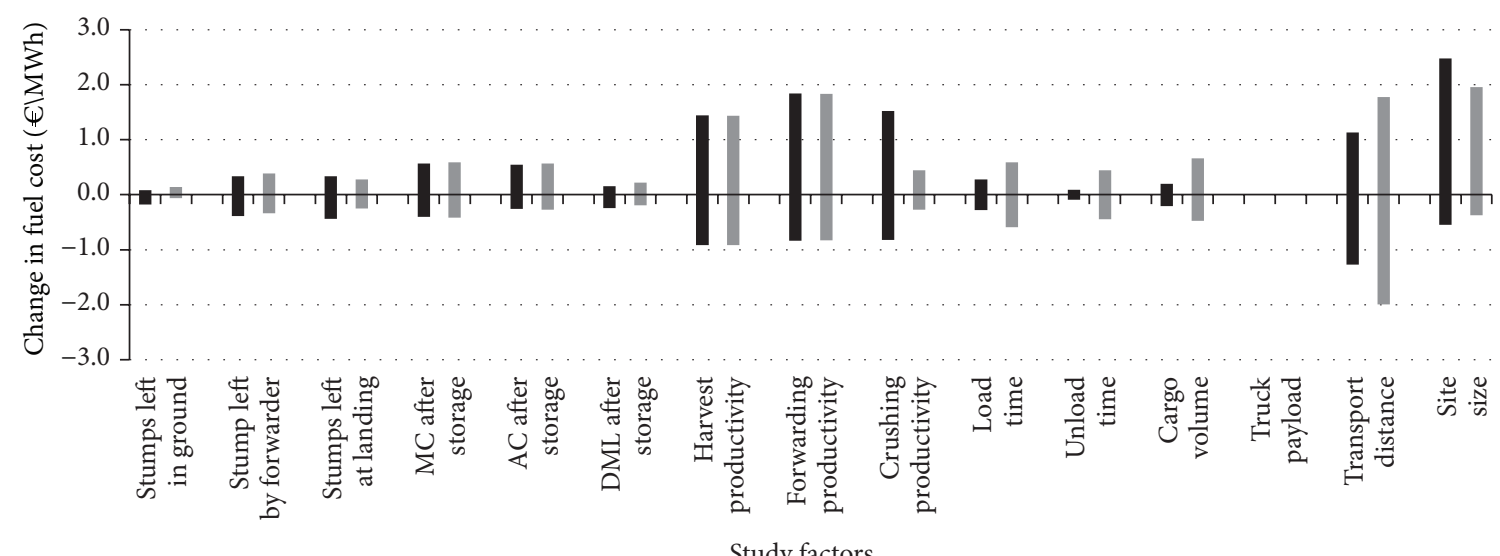

Study factors

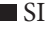

SII

Figure 3: Effects on fuel cost (€/MWh) of individually changing one factor at a time from its 0-level to its low and high levels.

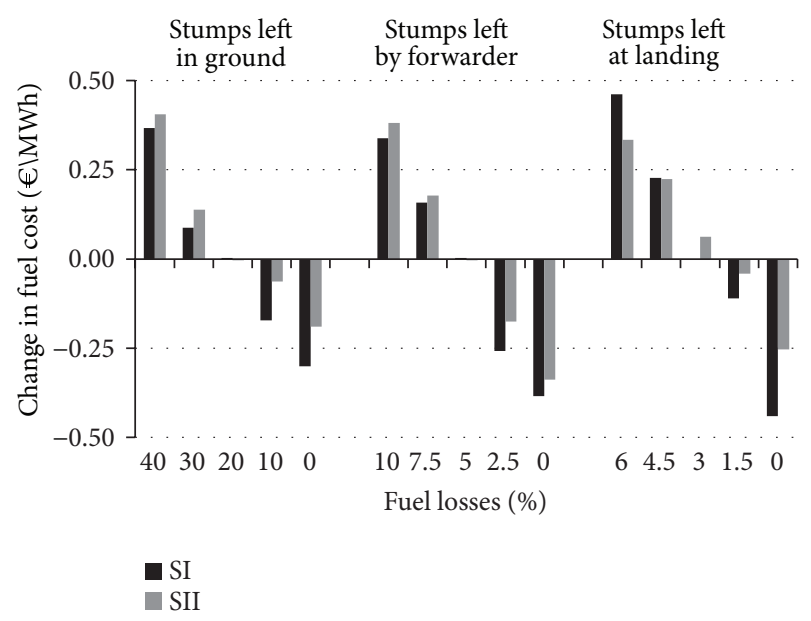

FIgURE 4: Change in fuel cost ( $€ / M W h)$ due to different percentage of stumps being left at various locations in systems SI and SII. The losses are in relation to ingoing material at each stage.

TABLE 5: Effect on fuel cost (€/MWh) of simultaneous changes in all factors related to machine productivity or operation time (SF7-11) from a low to a high case in systems (I) and (II).

\begin{tabular}{lcc}
\hline \multirow{2}{*}{ System } & \multicolumn{2}{c}{ Fuel cost $(€ / \mathrm{MWh})$} \\
& Low case & High case \\
\hline S (I) & 21.6 & 13.4 \\
S (II) & 21.6 & 13.9 \\
\hline
\end{tabular}

decrease of $38 \%$ and $36 \%$ was observed for systems (I) and (II), respectively (Table 5).

Changes in the extended parameter analyses which were most influential for fuel cost were harvest productivity, closely followed by forward productivity (Figure 6). Proper selection of stump harvest site and machine type can help to keep machine productivity parameters at high levels. However, many other factors are also involved (e.g., operator),

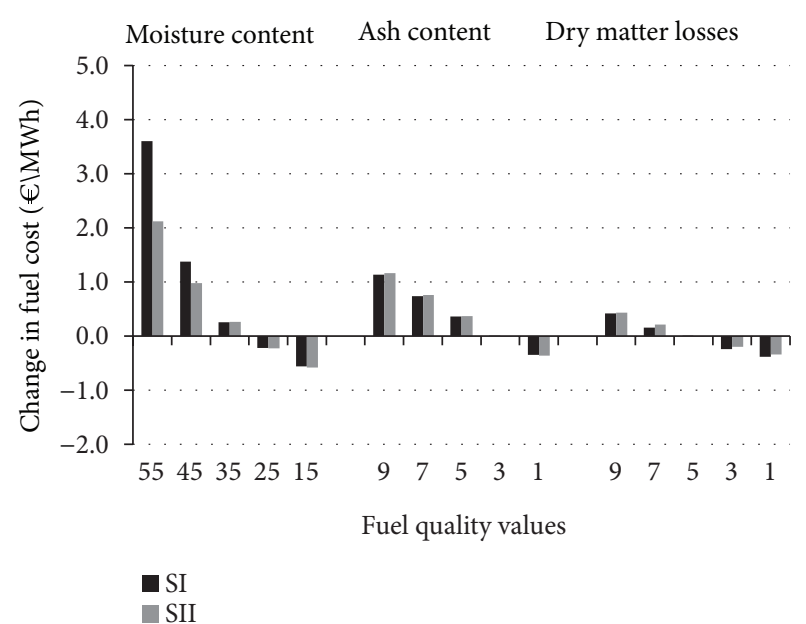

FIGURE 5: Change in fuel cost (€/MWh) due to different storage outcomes regarding moisture content, wet basis (\%), ash content, dry basis (\%), and dry matter losses (\%) in systems SI and SII.

which makes the outcome difficult to predict. Nevertheless, efforts have to be made to improve productivity. Avoiding low productivity is crucial for system economics.

3.5. Shorter Storage Time through Sieving. The effects of introduction of sieving equipment at the landing together with comminution when handling heavily contaminated material were simulated. Rejecting $25 \%$ of dry mass through sieving and reducing AC from 20 to $5 \%$ meant that $11 \%$ of dry mass on an ash-free basis ended up in the reject fraction. A fuel cost of $18.4 € / M W h$ was obtained when sieving of heavily contaminated material was tested. Transporting the same material directly to an end user without comminution and sieving resulted in a fuel cost of $20.2 € / \mathrm{MWh}$. Considering the fact that sieving can shorten the required storage time needed to reach an acceptable fuel quality, sieving becomes an interesting alternative, especially for contaminated stumps. 


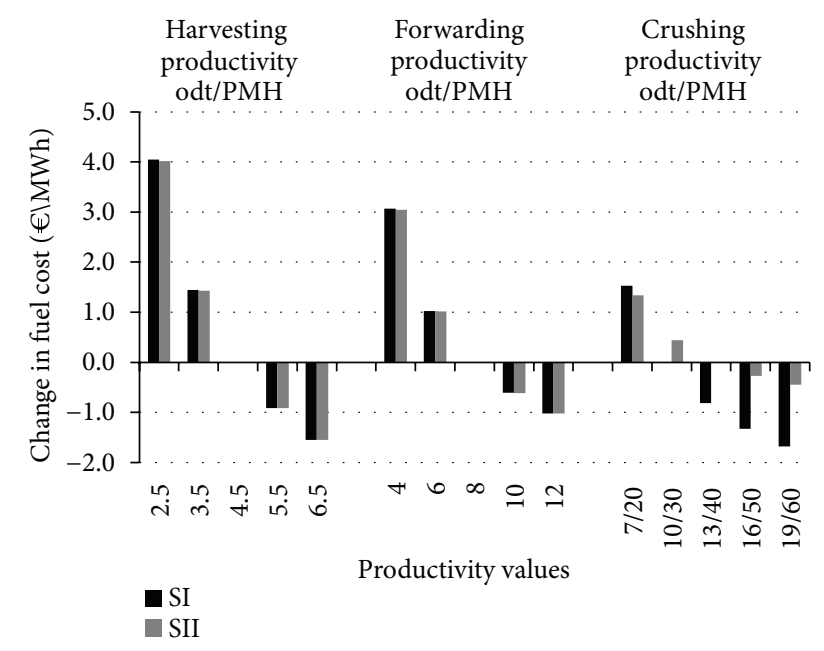

FIGURE 6: Influence of changes in machine productivity values on fuel cost ( $€ / \mathrm{MWh})$ in systems SI and SII. When two values are given, the first is for system SI and the second for system SII.

Shorter storage times facilitate regeneration at the clear cut area. Moreover, a more homogeneous fuel with assured quality is achieved by this operation. The fuel quality fluctuations that can sometimes be seen in stump fuel can be reduced in this system. An increased willingness among consumers to pay more for a cleaner high-quality fuel with less fine fraction was reported by Söderström [46], justifying use of sieving systems.

3.6. Truck Transport Parameters. Regarding transportation, the relevant study factors tested (SF10-13) were previously identified as areas for improvement [35]. The truck transport time between forest landing and end user is difficult to improve given a specific route, if delays are excluded. Time required for loading in the forest and unloading at the end user varies more. Different loading times are often a result of local landing, windrow conditions, machine operator, and work procedure. When unloading at a power plant, the biomass in system (II) is unloaded directly into a stationary grinder, whereas side tipping of truck and trailer is used in system (I). Queues at the plant might also affect the total delivery time. System (II) proved to be more sensitive to a change in loading/unloading time because its lower transport capacity resulted in more round trips given the same amount of fuel to transport and thereby more loading/unloading operations. A change in possible load volume (around $\pm 5 \%$ ) had more influence on fuel cost in system (II) than system (I) (Figure 7). More round trips were required to transport the same volume of biomass in system (II). Comparable cost changes due to a change in load capacity have been reported previously [35]. A changed payload did not cause any cost changes due to the fact that the load is limited by volume and not limited by weight given the quality parameters in the base case.

3.7. Site Characteristics. The initial number of stumps in the ground per site and the road transport distance to the end

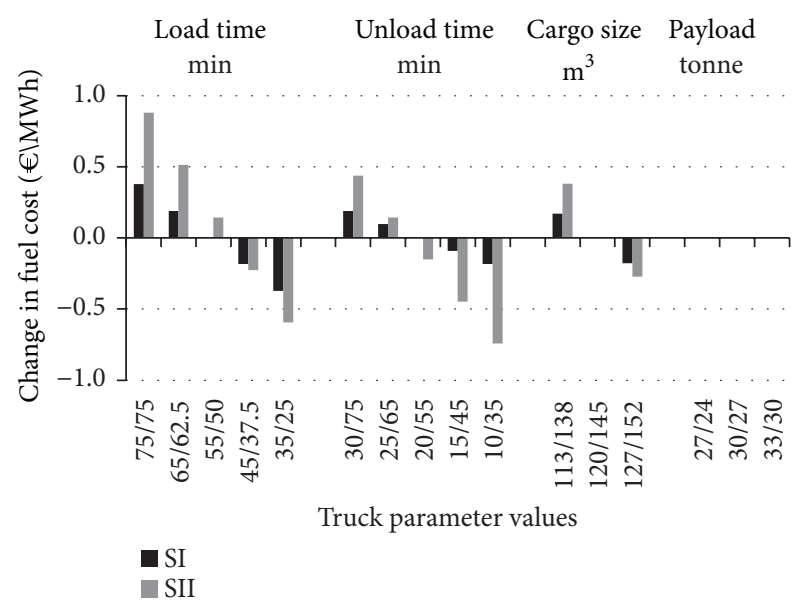

Figure 7: Influence on fuel cost (€/MWh) of changes in truckrelated properties. When two values are given, the first is for system SI and the second for system SII.

user were two factors strongly affecting the fuel cost. In general, the system where stumps were transported uncomminuted was more sensitive to distance, whereas the landing comminution system was more sensitive to the site size. The best system in different situations is shown by a responsesurface diagram (Figure 8). Site sizes of 75-600 odt stumps in the ground per site and one-way transport distance from forest landing to end user ranging from 10 to $150 \mathrm{~km}$ were examined. The steeper slope of the surface with increasing distance emphasizes the vulnerability of system (II) to long transport distances due to the bulkiness of the fuel. The lower load capacity of the loose stump trucks resulted in more loading, transport, and unloading activities. The smallest sites resulted in higher cost increases for system (I) than for system (II) (Figure 8). A general pattern was apparent, but since many parameters influence the results, a change in one of these might result in a change or at least a tweak to the surface.

Systems (I) and (II) were compared and the difference between the two systems was calculated (Figure 9). System (I) had higher costs for short distances $(10 \mathrm{~km})$, regardless of size. At distances of 30,50 , and $70 \mathrm{~km}$, harvesting site size determined the breakpoint between the two systems. System (I) had the lowest costs for distances above $90 \mathrm{~km}$, irrespective of site size. The exact transition point is valid under the circumstances defined in this study (0-level case defined in Table 1), but if some input parameters are changed a different point might be obtained.

3.8. Discussion of Methodology. Discrete-event simulation is widely used when studying logistics networks with interconnected activities, since analytic solutions for such problems are difficult to obtain. This study focused on two systems where machine dependency was weak and analytic solutions might be possible. However, since the fuel quality varied throughout the model and affected both transport properties and product value, a simulation approach was convenient. Real operations are often based on stochastic processes which influence the results. This study used a deterministic 


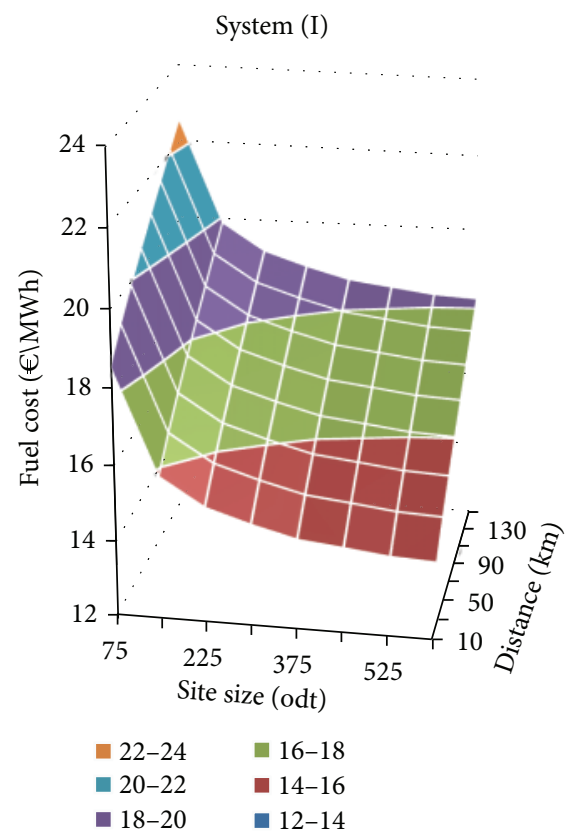

(a)

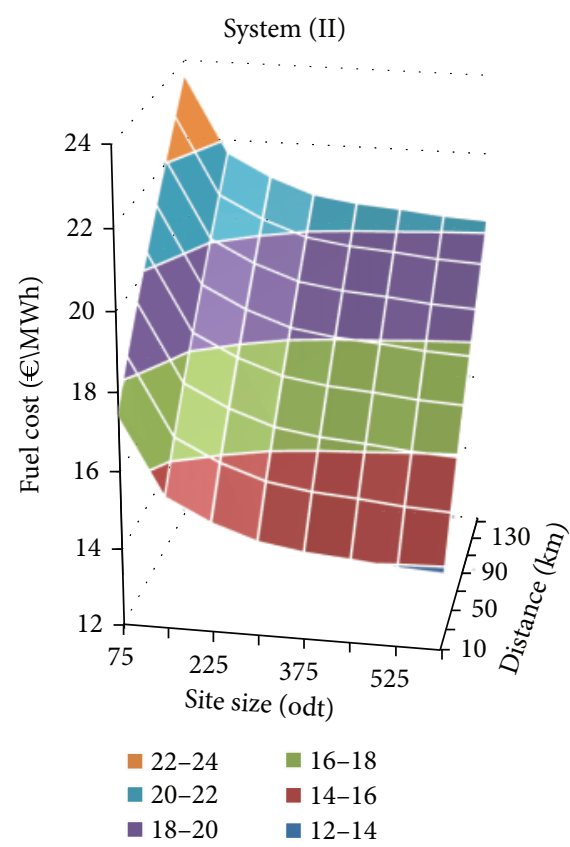

(b)

FIGURE 8: Response-surface diagram with varying stump transport distance (10-150 km) and stump harvesting site size (75-600 odt).

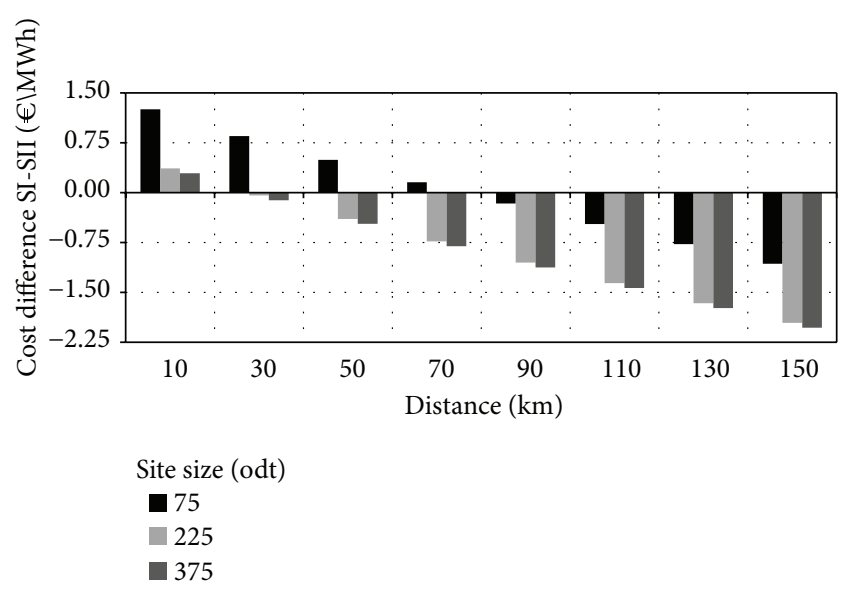

FIGURE 9: Cost difference between systems (I) and (II) for different values of stump harvesting site size (75-375 odt) and stump transport distance $(10-150 \mathrm{~km})$. A zero value indicates equally large costs.

approach focusing on parameter impacts rather than the exact delivery cost. A group of stump windrows with, for example, the same fuel quality values is unlikely in practice but the cost outcome of that was studied. Statements on system level are only valid under the circumstances defined for the study.

The aggregation level of the model was rather high and a more detailed model could be developed. The number of tonnes of stumps per site can, for example, be described as a function of number of hectares, number of stumps per hectare, tree species, and average stump diameter. A risk with a very detailed model is that the issue under study may be lost within the details. The model used here is an extended version of one developed previously [12], and some model structures were a result of that. The model logic is simple but captures the essence of the system.

The influence of one at a time factor changes on cost was tested for the base case setup. If all combinations of factor levels were tested, different values might be obtained. Parameter evaluation was performed for both combinations and isolated cases. In practice, all combinations of study factors are possible and likely, even though some of them are connected; for example, when studying a fuel with high MC, larger DML could be expected if the material had been stored for a long time. However, a wet fuel could also indicate fresh, newly harvested stumps with low DML. The present study focused on the cost effect of the parameters and not on how this effect was obtained.

When evaluating stump fuel systems, aspects other than fuel cost such as soil bearing, soil disturbance, carbon balance, nutrient export, and biodiversity must be considered [11].

\section{Conclusions}

The dynamic supply chain model developed here served as a good tool for analyzing different possibilities for handling and storing stump biomass throughout the supply chain system. All parameters tested had an effect on total system costs per unit energy delivered (fuel cost), indicating the importance of proper supply chain planning and management. A general conclusion that can be drawn is that material losses inflicted at early stages in the supply chain are preferable to losses at later stages, since the more the fuel is handled, the more the time and cost are invested in the material. It could 
also be concluded that leaving a given percentage of stump biomass in the ground at each site does not interfere with system feasibility. Sieving stumps at the roadside landing in combination with comminution, hence enabling shorter storage duration and ensuring better quality, could be a feasible strategy.

Fuel cost increased almost linearly with transport distance. Larger increases were evident in system (II) than (I). The influence of site size (odt) was nonlinear and more detrimental for system (I) than for system (II). The cost transition point between the two was at around $30-70 \mathrm{~km}$ and was also affected by harvesting site size. However, differences between the two systems were rather small, which implies that a change in input parameters might reverse the results. Moreover, proper storage was shown to play an important role in the supply chain, since cost could be reduced by around 13\% with well planned and executed storage. Avoiding poorly stored stumps with very high MC significantly reduced the fuel cost. However, based on the results from these simulations, site characteristics (site size and distance to end user) and machine productivity level were ultimately the main factors determining the fuel cost. One key to a profitable stump harvesting system is to ensure that machines can operate at a high level of productivity.

\section{Conflict of Interests}

The authors declare that there is no conflict of interests regarding the publication of this paper.

\section{Acknowledgment}

The authors are grateful to Skogforsk (The Forestry Research Institute of Sweden) for financial support through Research Program ESS:2.

\section{References}

[1] J. Routa, A. Asikainen, R. Björheden, J. Laitila, and D. Röser, "Forest energy procurement: state of the art in Finland and Sweden," Wiley Interdisciplinary Reviews: Energy and Environment, vol. 2, no. 6, pp. 602-613, 2013.

[2] “Skogliga konsekvensanalyser 2008-SKA-VB 08," Report 25, Skogsstyrelsen, Skogsstyrelsens förlag, 2008.

[3] E. Anerud and R. Jirjis, "Fuel quality of norway spruce stumpsinfluence of harvesting technique and storage method," Scandinavian Journal of Forest Research, vol. 26, no. 3, pp. 257-266, 2011.

[4] T. Kalliokoski, P. Nygren, and R. Sievänen, "Coarse root architecture of three boreal tree species growing in mixed stands," Silva Fennica, vol. 42, no. 2, pp. 189-210, 2008.

[5] L. N. Eriksson and L. Gustavsson, "Biofuels from stumps and small roundwood-Costs and $\mathrm{CO}_{2}$ benefits," Biomass and Bioenergy, vol. 32, no. 10, pp. 897-902, 2008.

[6] K. Kärhä, "Industrial supply chains and production machinery of forest chips in Finland," Biomass and Bioenergy, vol. 35, no. 8, pp. 3404-3413, 2011.
[7] K. Tran, X. Luo, G. Seisenbaeva, and R. Jirjis, "Stump torrefaction for bioenergy application," Applied Energy, vol. 112, pp. 539546, 2013.

[8] D. Eriksson, F. Weiland, H. Hedman et al., "Characterization of Scots pine stump-root biomass as feed-stock for gasification," Bioresource Technology, vol. 104, pp. 729-736, 2012.

[9] Y. Pu, D. Zhang, P. M. Singh, and A. J. Ragauskas, “The new forestry biofuels sector," Biofuels, Bioproducts and Biorefining, vol. 2, no. 1, pp. 58-73, 2008.

[10] J. Hjältén, F. Stenbacka, and J. Andersson, "Saproxylic beetle assemblages on low stumps, high stumps and logs: implications for environmental effects of stump harvesting," Forest Ecology and Management, vol. 260, no. 7, pp. 1149-1155, 2010.

[11] J. D. Walmsley and D. L. Godbold, "Stump harvesting for bioenergy-a review of the environmental impacts," Forestry, vol. 83, no. 1, pp. 17-38, 2010.

[12] A. Eriksson, L. Eliasson, and R. Jirjis, "Simulation-based evaluation of supply chains for stump fuel," International Journal of Forest Engineering, vol. 25, pp. 1-14, 2014.

[13] U. J. Wolfsmayr and P. Rauch, "The primary forest fuel supply chain: a literature review," Biomass and Bioenergy, vol. 60, pp. 203-221, 2014.

[14] M. Bertilsson, "Grovkrossning av stubbar [Stump shreddinga study in productivity]," Institutionen för Skoglig Resurshushållning, Sveriges Lantbruksuniversitet, Arbetsrapport, vol. 335, 2011.

[15] H. von Hofsten and P. Granlund, Effektivare Transporter om Stubbarna Grovkrossas Påavlägg, Haulage Gain from Crushing Stumps to Coarse Chips at Landing, Resultat Skogforsk, 2010.

[16] H. von Hofsten and M.-Å. Brantholm, "Kostnader och produktivitet i stubbskörd-en fallstudie (Productivity and costs in stump harvest systems - a case study)," Skogforsk Arbetsrapport 795, 2013.

[17] J. Laitila, T. Ranta, and A. Asikainen, "Productivity of stump harvesting for fuel," International Journal of Forest Engineering, vol. 19, pp. 37-47, 2008.

[18] M. Laihanen, A. Karhunen, and T. Ranta, "Possibilities and challenges in regional forest biomass utilization," Journal of Renewable and Sustainable Energy, vol. 5, no. 3, Article ID 033121, 2013.

[19] R. Jirjis, "Storage and drying of wood fuel," Biomass and Bioenergy, vol. 9, no. 1-5, pp. 181-190, 1995.

[20] M. Nylinder and T. Thörnqvist, Lagring av stubbved i fingerad miljö, Institutionen för skogsproduktion, Rapport 121, Sveriges lantbruksuniversitet, Garpenberg, Sweden, 1981.

[21] J. Laurila and R. Lauhanen, "Moisture content of norway spruce stump wood at clear cutting areas and roadside storage sites," Silva Fennica, vol. 44, no. 3, pp. 427-434, 2010.

[22] P. Rauch, "Stochastic simulation of forest fuel sourcing models under risk," Scandinavian Journal of Forest Research, vol. 25, no. 6, pp. 574-584, 2010.

[23] R. H. Ballou, Business Logistics Management, Prentice Hall, Englewood Cliffs, NJ, USA, 1992.

[24] J. Allen, M. Browne, A. Hunter, J. Boyd, and H. Palmer, "Logistics management and costs of biomass fuel supply," International Journal of Physical Distribution \& Logistics Management, vol. 28, pp. 463-477, 1998.

[25] D. Athanassiadis, O. Lindroos, and T. Nordfjell, "Pine and spruce stump harvesting productivity and costs using a Pallari KH 160 stump-lifting tool," Scandinavian Journal of Forest Research, vol. 26, no. 5, pp. 437-445, 2011. 
[26] S. C. Grado and M. Jeya Chandra, "A factorial design analysis of a biomass to ethanol production system," Biomass and Bioenergy, vol. 15, no. 2, pp. 115-124, 1998.

[27] M. R. Ghaffariyan, M. Acuna, and M. Brown, "Analysing the effect of five operational factors on forest residue supply chain costs: a case study in Western Australia," Biomass and Bioenergy, vol. 59, pp. 486-493, 2013.

[28] M. Acuna, L. Mirowski, M. R. Ghaffariyan, and M. Brown, "Optimising transport efficiency and costs in Australian wood chipping operations," Biomass and Bioenergy, vol. 46, pp. 291300, 2012.

[29] H. An and S. W. Searcy, "Economic and energy evaluation of a logistics system based on biomass modules," Biomass and Bioenergy, vol. 46, pp. 190-202, 2012.

[30] J. Banks, J. Carson, B. Nelson, and D. Nicol, Discrete-Event System Simulation, Pearson Education, Upper Saddle River, NJ, USA, 2010.

[31] L. Eliasson, P. Granlund, H. von Hofsten, and R. Björheden, "Studie av en lastbilsmonterad kross-CBI 5800 (Study of a truck-mounted CBI 5800 grinder)," Arbetsrapport 775-2012, 2012.

[32] M. Nordström, B. Hannrup, E. Anerud, T. Johannesson, H. von Hofsten, and L. Eliasson, "Validation of functions for calculating the quantity of forest fuel in stump harvest-a pilot study," Skogforsk Arbetsrapport 780-2012, 2012.

[33] H. von Hofsten, T. Johannesson, and E. Anerud, "Impact of stump splitting on harvest productivity," Skogforsk Arbetsrapport, vol. 759, 2012.

[34] H. von Hofsten, T. Johannesson, and E. Anerud, Comparative Study of Two Stump Lifting Heads, Biorex 50 and the Rotary Stump Cutter-Effects on Stump Procurement System from Lifting to Grinding on Landing, vol. 783 of Arbetsrapport Skogforsk, 2012.

[35] T. Ranta and S. Rinne, "The profitability of transporting uncomminuted raw materials in Finland," Biomass and Bioenergy, vol. 30, no. 3, pp. 231-237, 2006.

[36] W. E. Walker, P. Harremoës, J. Rotmans et al., "Defining uncertainty: a conceptual basis for uncertainty management in model-based decision support," Integrated Assessment, vol. 4, pp. 5-17, 2003.

[37] W. L. Oberkampf, S. M. DeLand, B. M. Rutherford, K. V. Diegert, and K. F. Alvin, "Error and uncertainty in modeling and simulation," Reliability Engineering and System Safety, vol. 75, no. 3, pp. 333-357, 2002.

[38] K. Kärhä and A. Mutikainen, "Testing two novel stump lifting heads in a final felling Norway spruce stand," in Proceedings of the 4th International Bioenergy Conference-Sustainable Bioenergy Business (Bioenergy '09), M. Savolainen, Ed., vol. 44, pp. 441-448, FINBIO, Jyväskylä, Finland, August 2009.

[39] O. Korpinen, T. Ranta, E. Jäppinen, E. Hämäläinen, and J. Laitila, "Forest fuel supply chain based on terminals and stumps," in Proceedings of the International Bioenergy Conference and Exhibition, M. Savolainen, Ed., Finnish Forest Research Institute, Jyvaskyla, Finland, September 2007.

[40] A. Leinonen, R. Impola, and S. Rinne, "Harvesting of stumps for fuel," in Bioenergy in Wood Industry, pp. 209-216, 2005.

[41] E. Anerud, "Stumps as fuel-the influence of handling method on fuel quality," Acta Universitatis Agriculturae Sueciae, vol. 2012, article 85, 2012.

[42] T. Thörnqvist, Logging Residues as a Feedstock for Energy Production-Drying, Storing, Handling and Grading, Sveriges Lantbruksuniversitet, Uppsala, Sweden, 1984.
[43] S. van Loo and J. Koppejan, The Handbook of Biomass Combustion and Co-Firing, Earthscan, Sterling, Va, USA, 2008.

[44] O. Balci, "Validation, verification, and testing techniques throughout the life cycle of a simulation study," Annals of Operations Research, vol. 53, no. 1, pp. 121-173, 1994.

[45] M. Pettersson and T. Nordfjell, "Fuel quality changes during seasonal storage of compacted logging residues and young trees," Biomass and Bioenergy, vol. 31, no. 11-12, pp. 782-792, 2007.

[46] J. Söderström, Grot ur Bränslekvalitetsynpunkt-En Studie i Attityders Inverkan, Efokus AB, 2009.

[47] K. Kärhä, "Comparison of two stump-lifting heads in final felling Norway spruce stand," Silva Fennica, vol. 46, no. 4, pp. 625-640, 2012.

[48] V. Lazdans, H. von Hofsten, A. Lazdins, and D. Lazdina, "Productivity and costs of stump harvesting for bioenergy production in Latvian conditions," in Proceedings of the 8th International Scientific Conference Engineering for Rural Development, pp. 28-29, Jelgava, Latvia, May 2009.

[49] B. Nordén, Sammanställning av Studier Påkrossar Och Flisare 2007-2009, Skogforsk, 2009.

[50] A. Asikainen and P. Pulkkinen, "Comminution of Logging Residues with Evolution 910R chipper, MOHA chipper truck, and Morbark 1200 tub grinder," International Journal of Forest Engineering, vol. 9, no. 1, 1998.

[51] J.-E. Liss, "Studier på nytt fordon för transport av skogsflis," Dalarna University, Wood Technology, Report, Arbetsdokument, Institutionen för Matematik, Naturvetenskap och Teknik, Falun, Sweden, 2006.

[52] R. Mortazavi and J. Johansson, "Road transport vehicles for hauling uncomminuted forest energy products in Sweden," International Journal of Forestry Research, vol. 2013, Article ID 402349, 7 pages, 2013.

[53] D. Lindberg, Stubbtransporter och Bränslekvalitet hos Stubbved [Stump Transport and Fuel Quality in Stumpwood], Arbetsrapport 220, Institutionen för Skoglig Resurshushållning, Sveriges Lantbruksuniversitet, 2008.

[54] "Saalasti Crush HF-a horizontal feed biomass processor," 2014, http://www.saalasti.fi/index.php/media-sv/broschyrersv?download=13:saalasti-crush-hf-463-en. 

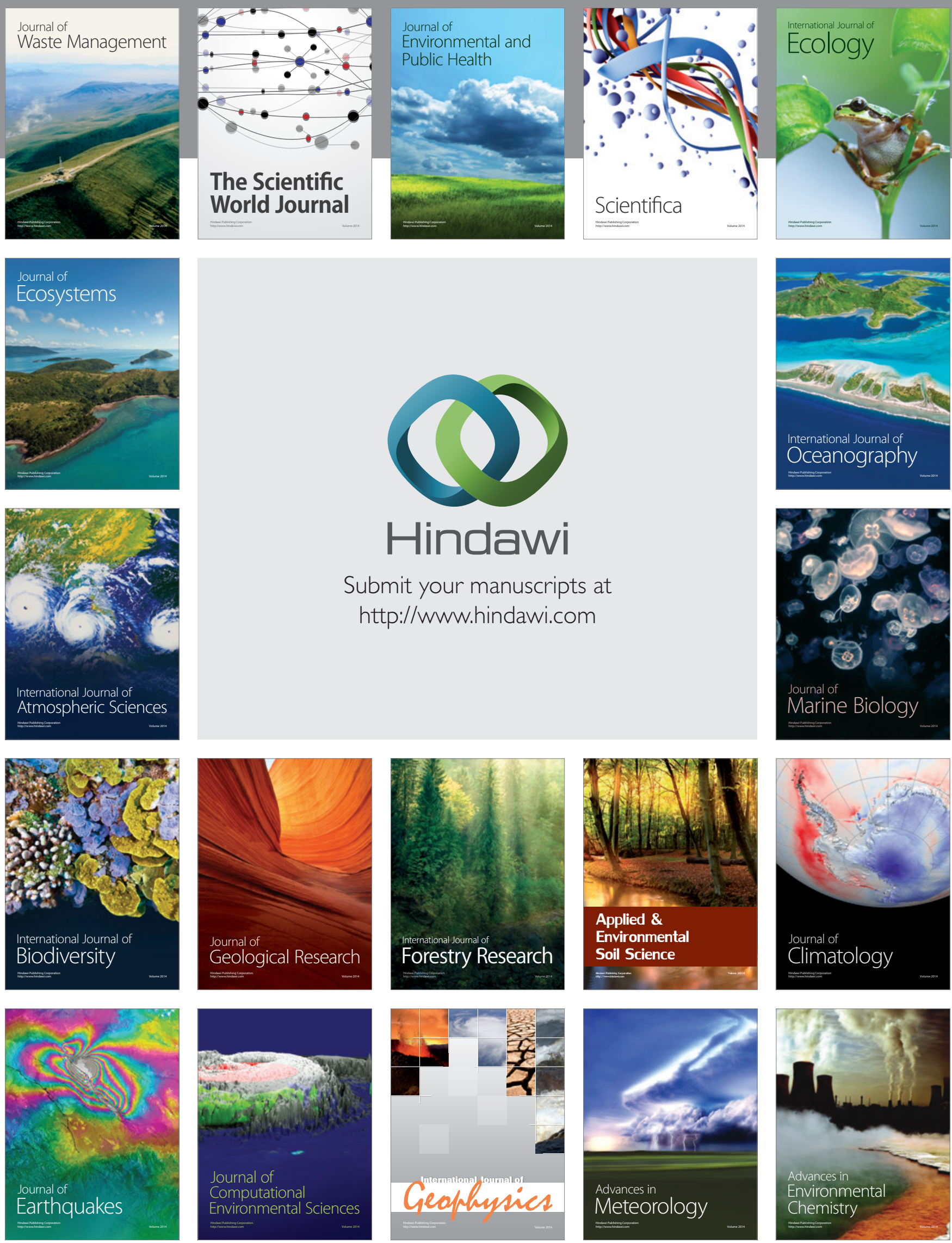